\title{
DEVELOPMENTS IN METHODS OF MICROSCOPY
}

A

WELL-ATTENDED symposium and exhibition, organized by the Royal Microscopical Society (Industrial Section) in collaboration with the Spectroscopy Group of the Institute of Physics, the Optical Group of the Physical Society and the Physical Methods Group of the Society of Public Analysts and Other Analytical Chemists, was opened at King's College, London, on March 20 by Prof. J. T. Randall. Prof. Randall welcomed the co-operation of the four societies concerned, which he said is a recognition that to-day microscopy is not the servant mainly of only one discipline, but of many.

The meeting consisted of three sessions of papers in the anatomy lecture theatre, while an exhibition of apparatus was staged in the Physics Laboratories at King's College. In the first session, Dr. A. E. J. Vickers surveyed the use of the polarizing microscope in organic chemical research. Optical measurements such as refractive index, birefringence, can be made, which characterize and identify materials. He showed a number of microscopes of different design, as well as accessories such as universal stages, for meticulously orienting crystals. Polarization was also the subject of two of the five short papers of the second session. Mr. E. G. Steward showed how X-ray analysis, together with examination of birefringence, can identify components of mixed minerals. He also exhibited a simple hot stage for studying polarizing microscope interference figures of crystals at raised temperatures : $200^{\circ}-300^{\circ} \mathrm{C}$. could easily be obtained with negligible heat loss, cooling arrangements being unnecessary. Dr. R. Barer discussed polarization of the fluorescent light emitted by certain crystals, and suggested this might be used for determining the orientation of molecular planes.

Mr. M. G. L. Curties discussed the testing of microscope objectives with the Baker-Smith interferometer, in which shear is obtained by birefringent elements. He showed interferograms of aberrant objectives and the effect of unsuitable cover glasses and immersion oils. Dr. H. H. Hopkins spoke on the influence of the illuminating aperture on optical images. The partial coherence of the light in the object plane depends on the aperture of the illuminating system. Some results obtained by a generalization of the diffraction theory of image formation were given, including the influence of aberration and condenser aperture on images of periodic structures, of lines of negligible width and of straight edges. Dr. M. H. F. Wilkins described a solid fused-quartz ultra-violet microscope water-immersion objective of N.A. $0 \cdot 90$, constructed with spherical surfaces. The quartz/aluminium reflecting interfaces are internal, so that atmospheric deterioration is prevented. Photomicrographs as examples of the performance of the objective were exhibited : the same field taken. in infra-red and in ultra-violet showed the relative quantities and distribution of hæmoglobin and nucleic acid in developing red cells.

Among other exhibits was a double-refracting interference microscope with variable phase, shown by Mr. F. H. Smith. The optically matched condenser and objective pairs with double-refracting components each exert a double-focus effect. The condenser illuminates axially separated planes of the specimen with the same portion of the luminous source, while the objective brings the two separated planes into coincidence in the image plane. The interference of the images is controlled by a doublerefracting phase-shifting system. Prof. S. Tolansky exhibited a device for showing the profile of a surface. The shadow of a thin opaque line thrown at an angle on to a flat surface under the microscope appears straight, but if the surface is corrugated the line faithfully contours the corrugations. An infra-red reflecting microscope of N.A. 0.8 and focal length $13.5 \mathrm{~mm}$. was demonstrated by Dr. W. C. Price; it is constructed with large mirrors to give a long working distance and to match the opties of an infra-red spectrometer. 'The focal length permits the objective te be used at the low magnifications necessary for infra-red work. Dr. P. M. B. Walker showed a densitometer for recording the density in photomicrographs by a double-beam system incorporating a circular density wedge, and he and Dr. H. G. Davies showed a photomultiplier attachment for photometric microscopy. Dr. W. E. Seeds exhibited an ultra-violet monochromator for use with a microscope of low aperture and high dispersion. It is a reflecting system involving two passages of light through a $60^{\circ}$ quartz prism : with a line source, large field areas can be illuminated monochromatically.

In Mr. J. R. King's apparatus for examining opaque objects by fluorescence microscopy, ultraviolet radiation suitably filtered from a high-pressure compact source mercury vapour lamp is reflected on to the specimen from above by a Chapman and Aldridge illuminator with aluminized surfaces, as modified in the Beck-Chapman illuminator. A new technique for examining fine particles of such materials as coal, which is only translucent when thin, was demonstrated by Dr. R. G. H. Boddy. The particles are collected by the 'delta' technique, the deposition of the dust on a slide being watched under the microscope to obtain an adequately sized and distributed sample. The particles are then crushed by a specially designed condenser while the process is under observation, the measurements of the particles and the manner and results of crushing affording new information about them. A twocircle goniometer of unconventional design to provide a robust and simple apparatus for measuring crystal angles was exhibited by Mr. W. T. Moore and Mr. L. W. Codd. Dr. R. Barer and Dr. W. Weinstien demonstrated a microscope lamp designed to fulfil the two conflicting requirements for Köhler illumination : for high-power objectives a large aperture has to be filled, but the field of view is small, while for low-power work the field is large and the aperture small. The new lamp uses one fixed lens and two interchangeable lenses to provide combinations suited to objectives and condensers commonly used.

A historical note was struck by Mr. F. C. Grigg, who illustrated, from the Royal Microscopical Society's collections, the development of the microscope slide. Leeuwenhoek made special microscopes for individual objects : the rotating object holder later became popular, with talc windows enclosing a variety of objects. The ivory slide held the field for more than a century, and early glass slides, also with a number of objects, were long and narrow. The first $3 \mathrm{in} . \times 1$ in. glass slides were covered with ornate 
paper covers : the present uncovered slide has now been used exclusively for upwards of fifty years.

Finally, among the exhibits was a small electron microscope shown by Mr. R. H. Horne.

The third session, a paper on cinemicrography, was given by Mr. R. MeV. Weston. He discussed the apparatus and general technique of filming through the microscope and the difficulties that arise when cinecamera and microscope are harnessed together, mentioning vibration, weight, size of film and apparent changes of speed with magnification. $\mathrm{He}$ showed lantern slides of a number of famous pieces of apparatus and finished with a fascinating film he had made, the only one so far to have been taken at 3,000 exposures per sec. through the compound microscope: it showed what happened to the mercury at the constriction in a clinical thermometer immersed in warm water.

Mary Dempsey

\section{BRITISH NON-FERROUS METALS RESEARCH ASSOCIATION \\ OPEN DAYS}

$\mathrm{D}$

URING the week beginning March 23 the British Non-Ferrous Metals Research Association held open days during which representatives of members and other industrial companies, university staffs and government scientific workers were invited to visit the laboratories at Euston Street, London, N.W.l. A total of more than eight hundred persons went during the week, and, at a press conference held on the first day, some fifty newspapers and periodicals were represented. The equipment of the laboratories was demonstrated, and the Association's present researches with some of those recently concluded were illustrated by exhibits.

The work of the Association covers every aspect of metallurgy, including extraction, melting and casting, working, mechanical and physical testing, corrosion, analysis and metal finishing. Major research projects, of which there are forty-two in hand at the moment, are selected from those problems which are of interest to groups of the Association's members and which can be more satisfactorily handled on a co-operative basis than in an individual works laboratory. Members co-operate with the Association's staff, which exceeds one hundred and fifty in number, by making available through a number of advisory committees knowledge within the industry on the problem in question; in some cases, members carry out in their own laboratories specific items in a research for which they have special facilities and try out some of the Association's investigations on a production scale for the benefit of other members.

The exhibits at the open days naturally referred mainly to the work actually carried out in the laboratories in Euston Street and were too numorous for comprehensive description. The following notes select a few items for special mention.

Pressing of aluminium alloys. One of the difficulties in the production of sheet-metal pressings in the aluminium-magnesium alloys, which are otherwise the most suitable for this purpose, is the appearance of markings in the less severely worked parts of the sheet due to uneven yielding. These are called stretcher/strain markings and are similar in appear- ance to those occurring in steels. The true nature of these markings has been investigated and the causes of their formation ascertained in the laboratories. From this basic knowledge practical recommendations for their avoidance have been made, and the effectiveness of the measures suggested has been established by works trials carried out with the collaboration of several members. The industry is now in a position to supply aluminium-magnesium alloy sheets which are not liable to these markings.

Improvements in bronze foundry practice. Over many years the Association's work in this field has established the principles governing the avoidance of gas and shrinkage unsoundness, and the present work is largely concerned with the application of this knowledge in industrial production. A special investigation is also being made in the use of insulated feeder-heads which not only improve the feeding of a casting but also greatly reduce both the weight of metal melted for a good casting and the labour involved in fettling.

Titanium. Although some exaggerated statements have been made about titanium, there is no doubt that its remarkable strength and corrosion resistance, coupled with its relatively light weight (intermediate between aluminium and steel), make it an extremely promising material for many engineering applications. The present high cost restricts very much its potential uses, but the prospects for the future are such as to make it important for Great Britain to play its share in the development of titanium alloys. The Association has investigations in this field in hand on behalf of the Ministry of Supply, and is provided with special equipment and experience in the techniques necessary for the handling of this highly reactive element.

Prevention of corrosion. Many of the applications of non-ferrous metals in engineering practice depend on their intrinsically high corrosion resistance, and the urge to develop better materials for particular applications is very pressing. In the field of condensertube alloys, the Association is pre-eminent. Aluminium brass, which is now very widely used in marine and land installations, was developed in the Association's laboratories, and the beneficial effect of iron additions in the 70/30 cupro-nickel alloy, which is widely accepted as the best all-round material for marine use, was fully established by the Association's work. This was followed by the development of copper-nickel-iron alloys of low nickel content, which are easily worked by the coppersmith and are resistant to corrosion by moving sea-water.

Similar work has been carried out on materials for the conveyance of fresh waters. For example, the occasional pitting to which copper water-pipes are subject has been traced in part to a film of carbon formed during the annealing operation which, when recognized, can easily be avoided, and in part to the absence from some waters of a naturally occurring corrosion inhibitor. Attempts are at present in hand to isolate and identify this inhibitor.

Metal economy. Researches designed to improve the efficiency of the manufacturing operations or to lengthen the service life in a particular application all promote the economical use of metals, and most of the Association's work comes in this category. Some researches have, however, been specifically aimed at problems in this field, such as the recovery of copper from pickle liquors, reduced consumption of zine in galvanizing and more effective use of nickel in electroplating. 